\title{
Research on Intelligent Yaw Control of Roadheader
}

\author{
Renjin Feng, Liangying Hao, Dongmin Gai, Xunan Liu, Jincheng Wang, Yang Zhao and Long Luo \\ College of Mechanical Engineering, Liaoning Technical University, Fuxin, 123000, China
}

\begin{abstract}
Under actual operating conditions, the yaw velocity of boom roadheader has direct influence on the efficiency and reliability of boom roadheader. The PID control method which uses neural network establish the intelligent control system of boom roadheader yaw, based on the MATLAB surface fitting technique, the relationship between the coefficient of coal and rock $f$, the cutting depth $B$ and the yaw velocity $V$ is obtained. The optimal yaw velocity generation module is established by using Simulink neural network, through simulation and residual analysis, it is found that the maximum residual value of the yaw velocity and optimal yaw velocity is within the feasible margin, it can achieve the accurate tracking of yaw velocity to the optimal yaw velocity and the automatic control of roadheader.
\end{abstract}

Keywords-optimal yaw velocity; intelligent control; neural network; residual analysis; feasible margin

\section{INTRODUCTION}

Boom roadheader is a combined unit, which enable cutting, loading, transporting, self walking and spray dust removing. With the comprehensive of actual mining face and the rapid development of coal mining mechanization, drivage speed of the coal mine is demanding higher and higher, the intelligent control of yaw velocity of the boom roadheader is the key ${ }^{[1,2]}$. Cantilever longitudinal roadheader is the key equipment of the tunnel excavation, with the expansion of the scope of its application, in the face of all kinds of complex working environment, the performance of the roadheader is put forward higher requirements. As the main working form of the roadheader, yaw cutting has gradually become the focus of research. The simulation based on virtual prototype technology can be used to obtain the optimal yaw velocity according to the intelligent control of the yaw of roadheader in various conditions. It provides an effective method for the optimization design and intelligent control of roadheader.

\section{THE Operational PRINCIPLE OF BOOM RoAdHEADER YAW}

\section{A. Basic Principle of Mechanical Structure of Yaw}

The yaw mechanism of boom roadheader consists of cutting head, cantilever, rotary table and rotary hydraulic cylinder. As shown in Figure I, the position of cutting head can be changed by adjusting space position of cantilever when cantilever roadheader works, and through the expansion of both sides of rotating hydraulic cylinder to achieve the reversing of horizontal plane and the swing left and right ${ }^{[3]}$.

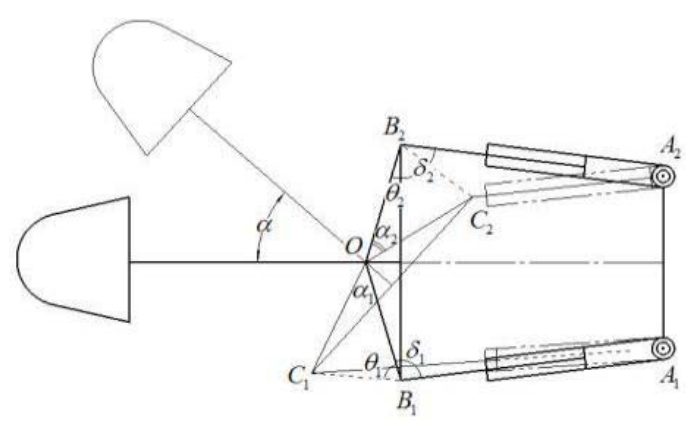

FIGURE I. YAW MECHANISM OF ROADHEADER'S BOOM

\section{B. The Influence of Yaw Velocity on Cutting Performance}

The yaw velocity has a very important influence on cutting performance of roadheader ${ }^{[4]}$. Taking a certain type roadheader cutting head as an example, the relationship between yaw velocity and maximum cutting area, theoretical productivity, maximum power consumption of cutting motor, maximum founder rate, maximum cutting resistance, cutting specific energy consumption is shown in the Figure II, the fluctuation coefficient of cutting thickness and cutting resistance under different yaw velocity are shown in the Table I.
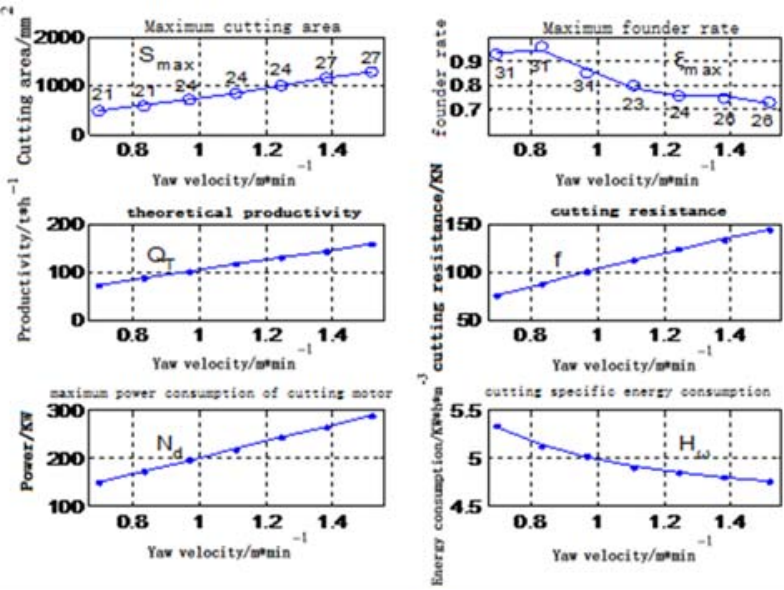

FIGURE II. YAW VELOCITY'S INFLUENCE ON CUTTING PERFORMANCE

TABLE I. CUTTING THICKNESS AND RESISTANCE'S FLUCTUATION COEFFICIENT UNDER DIFFERENT YAW VELOCITY

\begin{tabular}{clllllll}
\hline$V(\mathrm{~m} / \mathrm{min})$ & 0.690 & 0.832 & 0.969 & 1.106 & 1.243 & 1.38 & 1.517 \\
\hline$B(\mathrm{~mm})$ & 15.03 & 18 & 20.97 & 23.93 & 26.9 & 29.86 & 32.83 \\
$f$ & 0.040 & 0.044 & 0.048 & 0.048 & 0.052 & 0.028 & 0.028
\end{tabular}

In the working process of roadheader, the cutting thickness increases with the increase of the yaw velocity. As shown in Figure II and Table I, with the increase of the yaw velocity, the 
maximum cutting area, theoretical productivity, cutting resistance and power consumption of the cutting motor are approximately linear. In the process of increasing yaw velocity, with the increase of picks' cutting thickness, the cutting area is increasing, and the cutting shape is close to square, maximum rate of founder rises slowly; When it reaches the maximum value, it decreases with the increase of the yaw velocity, when the yaw velocity is greater than $1.4 \mathrm{~m} / \mathrm{min}$, the downward trend becomes faster; The cutting specific energy consumption shows a nonlinear decreasing change and the rate of change is decreasing. When the cutting motor power is selected, then, according to the cutting performance information provided in Figure II and Table I to select a yaw velocity which can not only meet the requirements of the cutting motor power but also make the cutting resistance fluctuation coefficient, cutting energy consumption smaller, the founder rate, the larger cutting area.

\section{Generation of Optimal YaW Velocity of ROADHEADER}

The internal structure of roadheader yaw system is complex, it is difficult to study in a simple and direct way. A variety of multi module library in MATLAB can be used to solve multi field joint simulation and control problems. As shown in Figure III, the surface fitting model of neural network is established by using surface fitting toolbox in MATLAB, the surface fitting of the yaw velocity, the strength coefficient of coal and rock and the cutting depth is realized. Taking the actual work of a model as an example, the working parameters were fitted by neural network surface fitting module, then the fitting curves of the yaw velocity, the strength coefficient of coal and rock and the depth of cutting are obtained. As shown in Figure IV, the horizontal coordinate is the strength coefficient of coal and rock $f$, the ordinate is the cutting depth $B$, the $\mathrm{Z}$ direction is the yaw velocity $V, Z(1)-Z(16)$ are fitting curves under corresponding parameters.

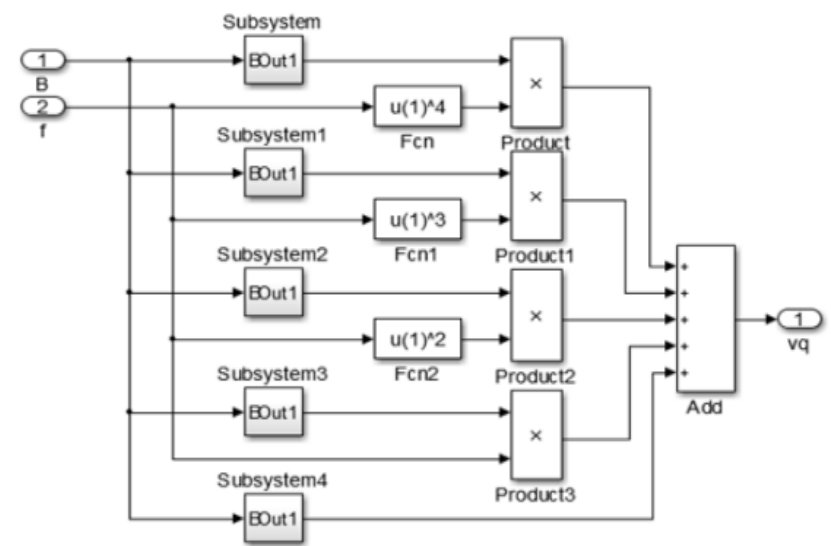

FIGURE III. NEURAL NETWORK FITTING MODULE

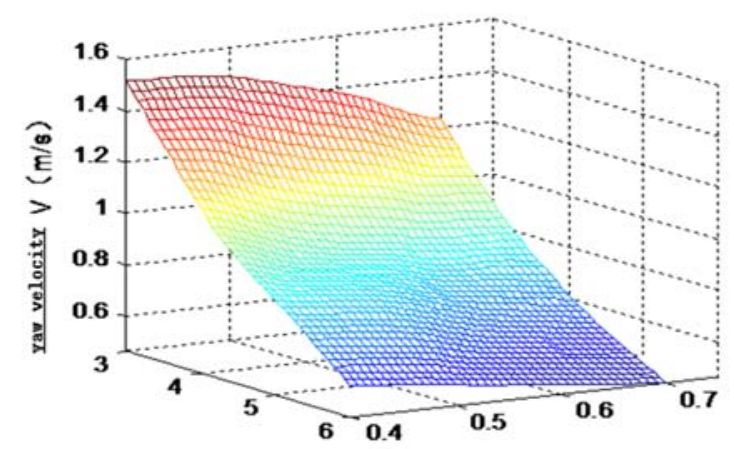

Solidity coefficient $f$

Cutting depth B ( m)
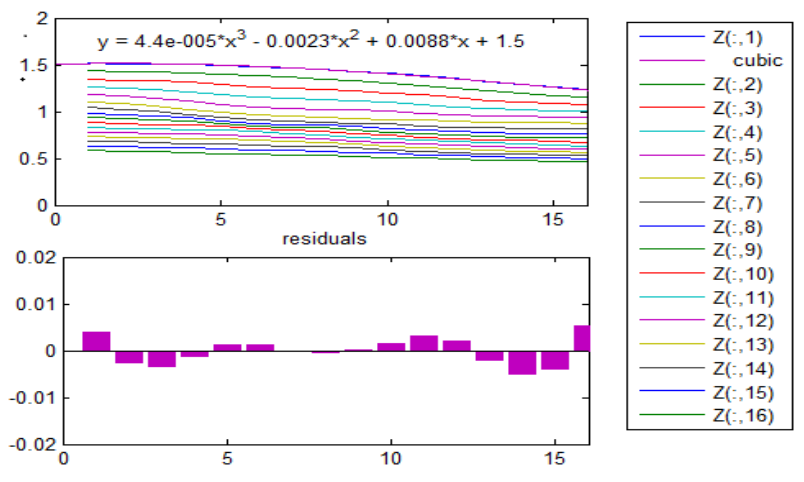

FIGURE IV. NEURAL NETWORK SURFACE FITTING AND RESIDUAL GRAPH

Based on the residual analysis of the surface fitting residuals in Figure IV, the maximum residual value of yaw velocity and optimal yaw velocity is only $0.005 \mathrm{~m} / \mathrm{min}$, the feasible margin of the maximum residual value of the yaw velocity and the optimal yaw velocity is defined as $\gamma$, (The feasible margin is equal to the ratio of the optimal yaw velocity to the absolute value of the difference between the yaw velocity and the optimal yaw velocity), when the feasible margin is less than or equal to $1 / 1000$, it can be considered that the yaw velocity can accurately track the optimal yaw velocity, the accuracy of the fitting module is verified.

\section{THE EsTABLISHMENT OF INTELLIGENT CONTROL SYSTEM}

\section{A. Intelligent Motor Control System}

The roadheader yaw mechanism is an integrated system of many fields, such as hydraulic, control, power electronic system, and so on. It has the characteristics of multi variable, nonlinear, dynamic and strong coupling ${ }^{[5,6]}$. Because the work boring machine face has many complicated conditions, in order to improve the work efficiency, a set of intelligent speed control system should be introduced in the roadheader yaw system. Based on the reliable operation of the key parts of the roadheader, the aim of realizing the self adjustment of the yaw velocity with the change of the geological conditions at work could be achieved. 


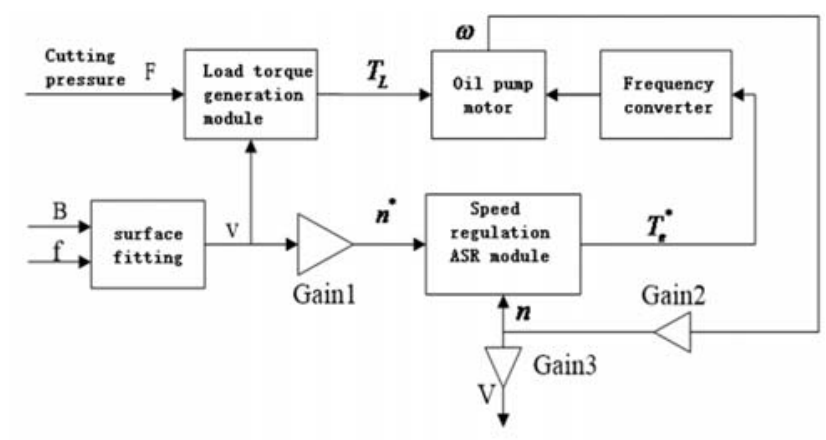

FIGURE V. THE SCHEMATIC OF OIL PUMP MOTOR SPEED CONTROL SYSTEM

As shown in Figure $\mathrm{V}$, when the excavator is working, the cutting depth B and coal firmness coefficient $f$ by fitting technique for generating neural network surface corresponding to the yaw velocity of $V, V$ after a Gain translated into the ideal speed of oil pump motor speed $n^{*}$; at the same time, the pressure sensor is installed on the cutting teeth on the measured the cutting teeth of the instantaneous pressure $\mathrm{F}$ and actual yaw speed V to introduce "load - torque generation module" to generate the oil pump motor actual load torque $T_{\mathrm{L}}$. There are differences between output speed $n$ and the ideal speed $n^{*}$ of the oil pump motor, both of them were introduced "ASR speed regulation module” then the ideal motor torque $T_{\mathrm{e}}{ }^{*}$ is obtained. The IGBT of inverter could achieve the purpose of regulating motor speed by changing the frequency of the stator voltage on the motor. It can be seen from the formula (1) that the change of the speed of the oil pump motor will cause the change of the oil supply quantity of the hydraulic system, and then affect the expansion speed of the hydraulic cylinder $V$ in order to achieve the purpose of controlling the yaw velocity of roadheader.

Theoretical flow rate formula of single acting vane pump:

$$
q=B Z \operatorname{Re} \sin \left(\frac{\pi}{Z}\right) * n
$$

the axial width of the rotor is $\mathrm{B}$; $\mathrm{Z}$ is the number of blades; $\mathrm{R}$ is the inner surface of the stator; the eccentricity between the stator and the rotor is e.

\section{B. Intelligent Control Based on PID}

The cross cutting of roadheader is a very complicated process which is hard be described by a simply mathematical model and it is a typical multi parameter control system. Because of the mutual coupling between the motion parameters and the control parameters, it is difficult to determine the specific functions of each parameter in the control process, therefore, it is difficult to use the general method to control. Proportional, integral, derivative (PID) controlled by deviation controls are the actual production of the strongest vitality, the most widely used control methods ${ }^{[7]}$. In order to achieve the purpose that the yaw velocity of the rotary hydraulic cylinder is compatible with the working load, the cutting pressure F can be monitored in real time. When the $\mathrm{F}$ is changed, the speed of the oil pump motor $n$ is adjusted in time to control the yaw velocity so as to achieve the purpose of intelligent control.
During the working process of the boom roadheader, the cutting head is driven by a cutting motor to rotate, cutting the coal and rock with the picks. And through the rotation and lifting hydraulic cylinder driven cantilever swing to achieving in cutting any position. When the roadheader is working, the cutting motor is in constant power state. Under normal circumstances, the greater the cutting resistance of coal and rock, the greater the need for cutting torque, the lower the yaw velocity of the cantilever ${ }^{[8]}$. In order to make the roadheader can realize the intelligent yaw, it is necessary to control the oil pump motor, the principle of the control system is shown in Figure VI. It can be seen from Figure VI that the intelligent control system consists of three parts: the detection device, the controller and the drive system. The detection device is a pressure sensor installed on the cutting teeth of the roadheader, and the pressure of the picks are monitored in real time. The detection signal is sent to the controller by the $A / D$ converter after filtering. The driving system is composed by a frequency converter of controlling the speed of the oil pump motor. The control system is based on the control algorithm of the PID neural network, and the control parameters are sent to the frequency converter by the drive module, so that the oil pump motor can work at a proper speed. At the same time, the control system monitors the pressure state of the cutting gear in real time, and adjusts the speed of the cutter to adapt to the change of working conditions, so as to ensure the high efficiency and stable operation of the roadheader.

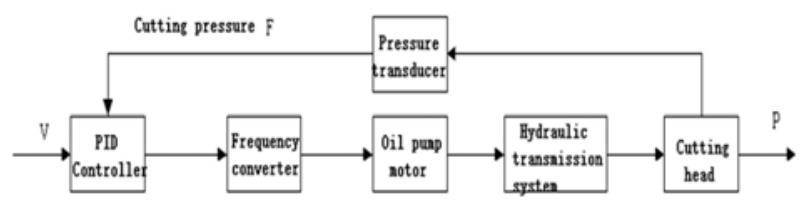

FIGURE VI. INTELLIGENT CONTROL SYSTEM OF ROADHEADER YAW

\section{Application of Intelligent Speed Control System Simulation}

During the working process of roadheader, the cutting depth and the rock strength coefficient of coal rock will be changed, and the cutting depth and the coefficient of rock and rock strength will be kept constant in a certain condition. However, due to the inclusion of coal seam and coal gangue will make the coal rock strength coefficient of this important cutting parameters of the abrupt change, resulting in the change of the size of the cutting force and then affect the working conditions of the roadheader. Taking the condition of $f=8$, $B=0.6 \mathrm{~m}$, in order to accurately reflect the influence of the change of coal rock solidity coefficient on the whole intelligent speed control system. The simulation of coal rock firmness coefficient $f$ is carried out, namely, using sine wave plus mutation signal and the benchmark coal rock coefficient of 8 . The coal and rock strength coefficient curve after superposition is shown in Figure VII and the cutting depth remains unchanged as shown in Figure VIII. The simulation parameters are fitted by neural network fitting model and the optimal yaw velocity of the roadheader is recommended as shown in Figure IX which is shown that the yaw velocity can reach the optimal yaw velocity quickly with the change of the coal rock solidity coefficient. In 
order to fully reflect the change of cutting parameters in the working process of the roadheader, the cutting depth is also simulated, and the simulation curve is shown in Figure X. When the coefficient of rock strength and the depth of the coal are changed simultaneously, the yaw velocity curve is shown in Figure XI. It can be seen from the figure that the intelligent speed control system can achieve the purpose of adjusting the yaw velocity with the change of geological condition, it provides an important reference for the optimization design and intelligent control of roadheader.

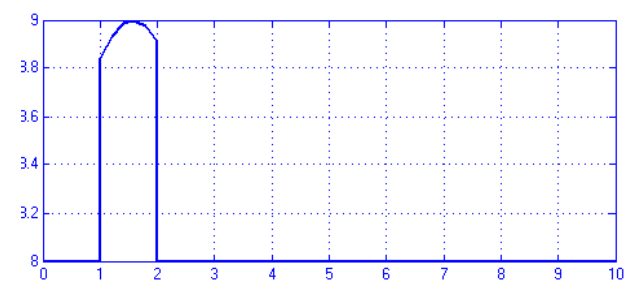

FIGURE VII. THE SIMULATION OF STURDINESS DEPTH CURVE

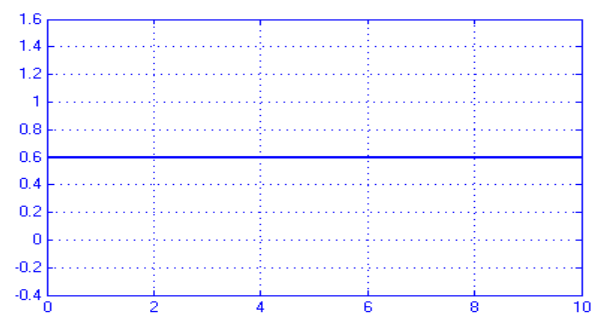

FIGURE VIII. THE SIMULATION OF CUTTING

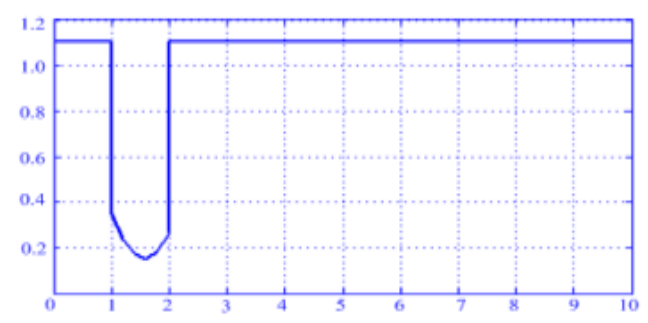

FIGURE IX. THE SIMULATION OF OPTIMAL YAW VELOCITY

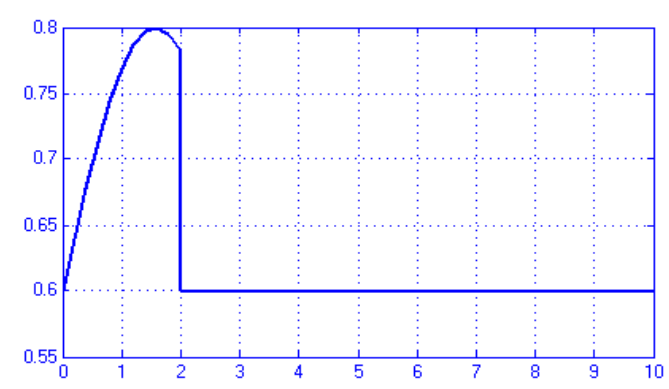

FIGURE X. THE SIMULATION OF CUTTING

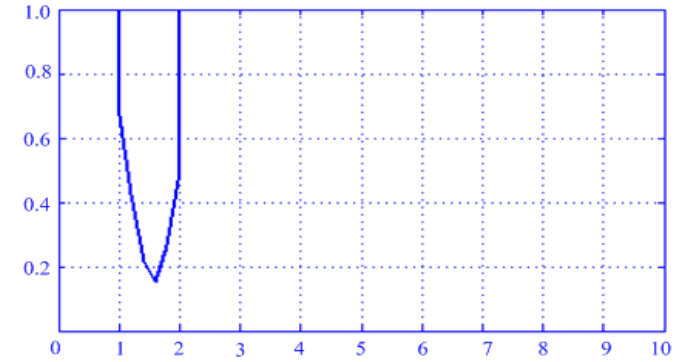

FIGURE XI. THE SIMULATION OF OPTIMAL YAW VELOCITY

\section{CONCLUSION}

(1) The optimal yaw velocity generation module of roadheader is built by neural network surface fitting technique and the optimal yaw velocity is obtained, which realizes the purpose of intelligent adjustment the yaw velocity with the change of geological condition.

(2) Through the simulation analysis of the virtual prototype of a roadheader, it is found that the maximum residual value of yaw velocity and optimal yaw velocity is only $0.005 \mathrm{~m} / \mathrm{min}$, it is of great practical significance for the research of mining automation to realize the accurate tracking of yaw velocity to the optimal yaw velocity.

\section{ACKNOWLEDGMENT}

I am greatly indebted to my supervisor, Professor Liu Xunan, for his valuable instructions and suggestions on my thesis as well as his careful reading of the manuscript.

I feel grateful to all the teachers in the College of Mechanical Engineering, Liaoning Technical University who once offered me valuable courses and advice during my study. My sincere thanks are also given to Pro. Zhao Lijuan and Gai Dongmin from whose lectures I benefited greatly.

Last but not least, I owe much to my friends and classmates for their valuable suggestions.

Project fund: National College Students Innovation and entrepreneurship training program (201610147000074).

\section{REFERENCES}

[1] Tian Jie,Research on automatic cutting control system of roadheader[D].Bei Jing:China University of Mining and Technology(Bei Jing), 2010

[2] Zhao Lijuan. Ma Yongzhi,Research on reliability of shearer cutting unit based on multi body dynamics[J].2009.34(9):1271-1275

[3] Huang Xiangyang,Research on adaptive cutting technology of roadheader[J].Wu Han :Wuhan University of Technology, 2013.

[4] Liu Chunsheng,Modeling and Simulation of horizontal swing mechanism of boom type roadheader[J].Heilongjiang Institute of Science and Technology, 2008.

[5] Zhao Lijuan and Sun Xiaona,Modeling and Simulation of cantilever roadheader.[J].Fu Xin:Liaoning Project Technology University.2013.

[6] Li Rui,Research on the position and orientation parameter detection system of the cantilever roadheader[J].China Mining University(Bei Jing).2012.

[7] Zhang Jianguang,Research on intelligent control strategy for adaptive cutting of cantilever roadheader[J].Tai Yuan.2014.

[8] Qiu Zhanyi,Intelligent control and Simulation of electro hydraulic proportional radial piston pump based on PID neural network[J].2010. 